\title{
Co-national Obligations \& Cosmopolitan Obligations towards Foreigners
}

\section{Ambrose Y. K. Lee}

(The definitive version is available at www.wileyonlinelibrary.com/journal/ponl)

This paper targets a very specific audience: those who think that there are co-national obligations because of Hurka's argument for them, and that these co-national obligations take priority over some cosmopolitan obligations towards foreigners.

As I take them in this paper, cosmopolitan obligations are derived by applying a theory of justice onto the global arena, without any discrimination based on national affiliations. In this paper, I shall consider two theories of justice. ${ }^{\mathrm{i}}$ The first one (J1) is prioritarianism, which states that benefitting those that are worse off matters more, because they are at a lower absolute level (Parfit 1998, pp. 12-13). I take this to imply that justice requires, in the first instance, benefitting the worst offs. The second one (J2) is egalitarianism, which argues that justice requires equality in certain aspects, i.e. welfare, resources, opportunities etc. When applied onto the global arena, we have - corresponding to J1 - (GJ1) cosmopolitan obligations to benefit the worst offs whatever their national affiliations; or we have - corresponding to J2 (GJ2) cosmopolitan obligations to, through redistribution, benefit those who are worse off than us whatever their national affiliations, so that we all would be equal in the relevant aspects. Accordingly, when these cosmopolitan obligations are directed to foreigners (i.e. it is foreigners who (in GJ1) are the worst offs, or (in GJ2) are worse off than us), then I take them to be cosmopolitan obligations towards foreigners.

One way to resist these cosmopolitan obligations is to argue for the existence of co-national obligations (Miller 2007, pp. 31-34), and that these co-national obligations have priority over cosmopolitan obligations towards foreigners. ${ }^{\text {ii }}$ Of course, even the most ardent nationalist does not argue that all cosmopolitan obligations towards foreigners are trumped by co-national obligations. Miller, for example, argues that for certain cosmopolitan obligations towards foreigners which are based on the requirements of basic human rights, co-national obligations do not take priority over them (Miller 2007, pp.47-50). ${ }^{\text {iii }}$ Thus the claim that I shall be considering in this paper is this: there are co-national obligations that have priority over certain cosmopolitan obligations towards foreigners, namely those in GJ1 and GJ2.

In the following, I shall argue against an argument that one can offer in support of the above claim. This argument appeals to Hurka's account of the existence of co-national obligations, and based on that, argue that these co-national obligations have priority over cosmopolitan obligations towards 
foreigners. I shall argue that if we look at Hurka's account more closely, it surprisingly gives one a reason to fulfil one's cosmopolitan obligations towards foreigners first before fulfilling one's co-national obligations.

I choose to focus on Hurka in this paper for a number of reasons. First, even though (as I shall show later in this paper ) Hurka's account can readily be developed to argue for the claim that there are conational obligations that take priority over certain cosmopolitan obligations towards foreigners, seldom is it taken seriously in recent literature which aim to argue against that claim. Most of them, in contrast, focus their arguments against other accounts, e.g. Miller's and Tamir's. ${ }^{\text {iv }}$ Second, even when Hurka 's account is considered in recent literature, his account is portrayed as a contractualist account, i.e. co-national obligations take priority over certain cosmopolitan obligations towards foreigners because co-nationals have particularly strong claims over the benefits that they have jointly produced. ${ }^{v}$ But, as will become clearer in the following paragraphs, there is another way to understand Hurka's account, and that is as an argument by analogy for co-national obligations, i.e. by drawing an analogy with other kinds of relationships where special obligations justifiably exist. Third and finally, as an argument by analogy for co-national obligations, Hurka's account seems like an interesting alternative to other such arguments that draw the analogy with friendships. ${ }^{\mathrm{vi}}$ In contrast, Hurka's account draws the analogy with families instead (Hurka 1997, pp. 152-155). With all this in mind, let me first start with Hurka's account for the existence of co-national obligations.

According to Hurka, the following two conditions justify the existence of co-national obligations (Hurka, 1997, pp. 150-153):

1) The co-nationals have a shared history.

2) That shared history is all things considered valuable, where what makes it valuable is either (a) a history of shared suffering (e.g. under a colonial power) (b) a shared history of mutual benefit (e.g. through creating a welfare or educational system) or (c) a shared history of jointly benefiting others (e.g. through defending other nations from attack).

Hurka justifies the first condition by analogy with a prime example of a relationship in which special obligations justifiably exist, namely the relationship between spouses (Hurka, 1997, p. 147). What grounds special obligations between spouses, according to Hurka, is the fact that they have a shared history. As he explains, '...it involves loving the person for certain historical qualities, ones deriving from his or her 
participation with one in a shared history. Thus I love my wife not only as trustworthy, intelligent, and so on but also as the person who nursed me through that illness, with whom I spent that wonderful first summer, and with whom I discovered that hotel on Kootney Lake' (Hurka, 1997, p. 150). This also applies to co-national relationships. As he says, 'What attaches them specially to this culture and its members are historical facts: that this is the culture they grew up in, that their conationals share with them a history of being shaped by, participating in, and sustaining this culture' (Hurka, 1997, p. 151).

However, as Hurka makes clear, this is only one of the conditions for the existence of co-national obligations between members of the same nation (Hurka, 1997, p. 151). A shared history need not justify genuine special obligations. For example, there was a shared history between people in Poland and those in Nazi Germany: the former were attacked and assimilated by the latter and the latter attacked and assimilated by the former. However, it is counter-intuitive to argue that, at that time Polish people owed special priority in their obligations to people from Nazi Germany, when compared to their obligations to people from China or Ethiopia, for example. Hurka concludes that the additional condition necessary for a relationship with a shared history to generate special obligations among its members is that this shared history should be all things considered valuable. He claims that what can make it valuable is either that it is a shared history of suffering, of mutual benefit between its members or where its members have jointly benefited other people (Hurka, 1997, pp. 150-151). This rules out relationships (e.g. like the Nazi/Poland case) where the shared history is not all things considered good. As Hurka says, '... I do not think a shared history justifies partiality when it is a history of doing evil... Whereas a shared history of doing good or suffering evil can justify duties of partiality, a shared history of doing evil cannot' (Hurka, 1997, 151-152).

Is Hurka's account for the existence of co-national obligations plausible? I frankly do not know for sure. ${ }^{\text {vii }}$ But let us assume that some nationalists find it plausible. They can then further develop Hurka's account to support the claim that there are co-national obligations that take priority over some cosmopolitan obligations towards foreigners, i.e. those in GJ1 and GJ2, with the following: A shared history can be more or less valuable, and it can also be differentiated in terms of the density of interactions between those who have that shared history. If we accept that what justifies the existence of co-national obligations between members of a nation is the value of their shared history, it might then seem that other things being equal, the more valuable is the shared history, and the denser the interactions between those who have that shared history, the more priority can be accorded to the co-national obligations that are generated from the 
relationship with that shared history. Accordingly, the nationalists continue, there comes a point where the priority of co-national obligations overtakes that of GJ1 and GJ2. Thus those co-national obligations take priority over the cosmopolitan obligations towards foreigners in GJ1 and GJ2.

It seems possible that Hurka might endorse something like the above argument, as he says, “... the degree of concern that is justified toward conationals is considerably greater than toward non-nationals, since one's history with the latter scores very poorly on both dimensions" (Hurka 1997, p. 155). But this is not decisive, since he might be drawing a distinction between obligations of justice and obligations of beneficence. He might then argue that what the quote above refers to are obligations of beneficence. But when it comes to obligations of justice, i.e. cosmopolitan obligations towards foreigners, co-national obligations do not have priority over them, no matter how strong they are in themselves. I shall therefore proceed under the assumption that the above argument for the priority of co-national obligations is a development of Hurka's position, not that it is indeed his position.

However, as it stands, the argument is susceptible to an objection that turns on the content of these co-national obligations. As Caney says, “... even if we think that persons have special obligations to fellow national we cannot infer from this that they are obligations of distributive justice... The intuitive argument thus has to explain why these obligations are ones that people can claim as a matter of justice" (Caney 2005 , p. 134). The objection is that nowhere in the above argument for the existence of co-national obligations have one established that they are obligations of justice. But if they are not, then intuitively it seems rather implausible that they can have priority over cosmopolitan obligations towards foreigners, as the latter are obligations of justice.

To give the nationalists the benefit of doubt, I shall assume that co-national obligations are indeed obligations of justice. More specifically, their contents are derived from applying a theory of justice. But unlike cosmopolitan obligations where we apply the theory onto the global arena, we now only apply it onto the domestic arena - the nation in question. As before, I shall consider two theories of justice: (J1) the prioritarians, and (J2) the egalitarians. When applied onto the domestic arena, we have - corresponding to J1 - (DJ1) co-national obligations to benefit the worst offs in our nation; or we have - corresponding to J2 (DJ2) co-national obligations to benefit fellow nationals who are worse off than us, so that we would be equal in the relevant aspects. 
Accordingly, the claim that is under consideration, and of which the above nationalist argument seeks to establish, is this: the co-national obligations in DJ1 and DJ2 take priority over the cosmopolitan obligations towards foreigners in GJ1 and GJ2.

Recall that the ground for co-national obligations is that their shared history is all things considered valuable because it is a shared history of either (a) shared suffering, (b) mutual benefit, or (c) jointly benefiting others. If people choose to fulfil their co-national obligations, it is then a case of mutual benefit, thus (all other things being equal) their eventual shared history would be good. Alternatively, if people choose to fulfil their cosmopolitan obligations towards foreigners, then it is a case where they jointly benefit others, thus (all other things being equal) their eventual shared history would be good too. However, it seems that the eventual history would be better, if people fulfil their cosmopolitan obligations towards foreigners than if they fulfil their co-national obligations. This is because those who the cosmopolitan obligations are directed towards are in the worse situation than those who the co-national obligations are directed towards.

Allow me to explain with GJ1 and DJ1 first: Recall that DJ1 are directed towards the worst offs in one's nation, while GJ1 are directed towards the worst offs in the world. Insofar as GJ1 are directed towards foreigners, they must be more absolutely deprived than the worst offs in one's nation. This is because otherwise, GJ1 would be directed towards one's fellow nationals, not foreigners. If that is the case, then it follows that those who GJ1 are directed towards are in a worse situation than those who DJ1 are directed towards. This is because they are more absolutely deprived.

What about GJ2 and DJ2? I take it that what they aim for is the reduction of inequalities (in certain aspects); and the way to do so is by redistribution. By taking away some from the better offs and benefit the worse offs, we lower the level of the better offs and raise the level of the worse offs. Eventually the 'better offs' would be at the same level as the 'worse offs'. Thus the obligation is understood as benefitting those that are worse off than one such that we would be equal in the relevant aspects. What differs between GJ2 and DJ2 is the scope of individuals whose relevant aspects we are trying to equalize. For GJ2, it is everyone around the world, while for DJ2 it is only those who are members of the same nation as one. Thus in GJ2, they are directed to those around the world who are worse off than one; while in DJ2, they are only directed towards one's co-nationals who are worse off than one. 
But if the aim of these obligations is the reduction of inequalities, then they must be directed, in the first instance, to those who suffer from greater inequalities. This is because it is only by benefitting those who suffer from greater inequalities, can we reduce the gap between the better offs and the worse offs. If we only benefit those who suffer from lesser inequalities, then the gap between those who are even worse off and the better offs would not be reduced. Thus inequalities would not be reduced as a result. Accordingly, DJ2 would be directed to those who suffer from greater inequalities within one's nation; while GJ2 would be directed to those who suffer from greater inequalities within the world.

Now, if GJ2 are directed towards foreigners rather than co-nationals, then the foreigners must be suffering from a greater inequality than the co-nationals who DJ2 are directed towards. This is because if the co-nationals who DJ2 are directed towards suffer from as great an inequality as the foreigners, then GJ2 would also be directed towards those co-nationals. Thus if GJ2 are directed to those foreigners, without directing towards the co-nationals DJ2 are directed towards, they must be suffering from a greater inequality than the co-nationals. If that is the case, then it follows that those who GJ2 are directed towards are in a worse situation than those who DJ2 are directed towards. This is because they suffer from greater inequalities.

Given that, as illustrated, the foreigners who cosmopolitan obligations are directed towards are in a worse situation, there is therefore more goodness in alleviating them, when compared with alleviating the co-nationals that co-national obligations are directed towards. Thus this extra goodness is present if people choose to fulfil their cosmopolitan obligations while it is not present if people choose to fulfil their conational obligations. Although it is the case that both fulfilling one's co-national obligations and fulfilling one's cosmopolitan obligations are good in the sense that they are, respectively, cases of mutual benefit and jointly benefiting others, there is more good (other things being equal) in fulfilling cosmopolitan obligations than co-national obligations because the former involves alleviating people who are worse off, while the latter involves alleviating people who are less worse off. Thus, if co-national obligations are grounded in the goodness of the shared history between co-nationals, in the sense that it is a history of mutual benefit or benefiting other people (ignoring the shared history of suffering part for now), then fulfilling cosmopolitan obligations would contribute more good to the shared history of the co-nationals than fulfilling co-national obligations.

It seems very natural to suggest that one has a reason to do certain things which ground the thing that one believes truly to be good or valuable. For example, if one values living in a good neighbourhood 
and if what grounds the goodness of living in such a neighbourhood is that people who are living in such a neighbourhood are friendly towards each other, take care of each other etc, then it follows that there is a reason for one (who values living in a good neighbourhood) to be friendly to his neighbours and take care of his neighbours etc Similarly, if one really values one's co-national obligations, and what grounds such obligations is the goodness of the shared history of one's nation, and if so fulfilling one's cosmopolitan obligations towards foreigners contributes more goodness to the shared history of one's nation than fulfilling one's co-national obligations, then there is a reason for one to fulfil one's cosmopolitan obligations towards foreigners first before fulfilling one's co-national obligations. For by doing so one will make one's share history better than by focusing on co-national obligations. ${ }^{\text {vii }}$

Note that I am not saying that one has reason to do the things which justify whatever one values. What I am saying is that if one values something (e.g. X), then other things being equal, one would want the justification for $\mathrm{X}$ to be as strong as possible. And if doing certain things (e.g. Y) strengthens the justification for $\mathrm{X}$, then there is a reason for one (who values $\mathrm{X}$ ) to do Y. Thus if one really values one's co-national obligations, then one (other things being equal) would want the justification for them to be as strong as possible. Given that fulfilling one's cosmopolitan obligations strengthens the justification for them more than fulfilling one's co-national obligations, there is therefore a reason for one (who values one's co-national obligations) to fulfil one's cosmopolitan obligations first before fulfilling one's conational obligations.

Note also that the above conclusion is true, only if the nation that one is in is sufficiently just according to the cosmopolitan standard (i.e. J1 and J2 applied to the global arena). This is because if it is not, then there would also be cosmopolitan obligations directed towards one's fellow co-nationals. But if that is the case, then these fellow co-nationals cannot be in a worse situation than the foreigners who other cosmopolitan obligations are directed towards. They would either be as worst off as those foreigners, or suffer as great inequalities as those foreigners. Thus more accurately stated my conclusion is this: Given that one's nation is sufficiently just according to the cosmopolitan standard, then even if it is unjust according to the domestic standard (i.e. J1 and J2 applied to one's nation only), there is still a reason for one to fulfil one's cosmopolitan obligations towards foreigners first before fulfilling one's co-national obligations. ${ }^{\text {ix }}$ 
Let me quickly summarize here: My argument targets specifically those who think that co-national obligations have more priority than cosmopolitan obligations towards foreigners, because the shared history of the co-nationals is all things considered valuable in the sense that it is a history of shared suffering, a shared history of mutual benefit or of jointly benefiting others. But I argue that if that is the case, then there is a reason for one to fulfil one's cosmopolitan obligations towards foreigners first before fulfilling one's co-national obligations (provided that one's nation is sufficiently just according to the cosmopolitan standard, see above). This is because the foreigners that these cosmopolitan obligations are directed towards are in a worse situation than the co-nationals that co-national obligations are directed towards. Accordingly, there is therefore more good when, by fulfilling one's cosmopolitan obligations, one alleviates them than when one, by fulfilling one's co-national obligations, alleviate one's co-nationals. Thus the eventual shared history of one's nation would be more valuable if one fulfils one's cosmopolitan obligations towards foreigners, than if one fulfils one's co-national obligations. Committed nationalists who highly value their special ties with co-nationals and the co-national obligations generated from them would want the justification for their co-national obligations to be as strong as possible. And if what mainly grounds the existence of co-national obligations that take priority over cosmopolitan obligations is the value of the shared history of the nation, then there is a reason for them to fulfil their cosmopolitan obligations towards foreigners first before fulfilling their co-national obligations.

One might think that I am equating justice with value and goodness here. ${ }^{\mathrm{x}}$ But $\mathrm{I}$ think that is a mistake. I am not arguing that there is a reason for committed nationalists to fulfil their cosmopolitan obligations towards foreigners first before fulfilling their co-national obligations, because there is more good (or value) in doing so, and justice requires us to do what is of most good (or value). Rather, the reason that I have argued for here is grounded in their argument that co-national obligations take priority over cosmopolitan obligations towards foreigners, because of the value of their shared history. The thought is that since fulfilling their cosmopolitan obligations towards foreigners makes their shared history more valuable than if they fulfil their co-national obligations, there is therefore a reason for committed nationalists to fulfil their cosmopolitan obligations towards foreigners first before fulfilling their conational obligations. This is because doing so would strengthen the justification for their co-national obligations more than had they done otherwise.

My argument also seems to imply paradoxically that the more one helps foreigners, the more one is justified to help one's co-nationals. However imagine a group of friends who constantly help other 
people in a variety of ways and another group of friends who, although they do not harm other people, do not care much about those other people. We intuitively find that, all things being equal, if a moral claim arises among friends of their respective groups, those from the former group seems more justifiable in answering it than the latter group. If this is the case, then my argument's implication is not that paradoxical.

\section{i Endnotes}

Caney, for example, holds a combination of these two positions. See Caney 2005, pp.122-123.

ii Note that although Miller is explicitly against arguments that involve weighing co-national obligations with cosmopolitan obligations, he seems to be against a simple kind of weighing that does not take responsibilities into account, rather than weighing per se. Given the complexities of Miller's position, I shall not consider it in this paper. For critical discussions of it, see Caney 1999 and Tan 2011. The latter is a critical discussion of Miller's more recent position.

iii More specifically, it is the negative obligation to refrain from infringing foreigner's basic human rights, and the positive obligation to secure their basic human rights because of our outcome responsibility towards them. See also Miller 2007, pp.260-261).

iv $\quad$ For example: Brock 2009, pp. 248-273; Caney 2005, pp. 133-136; Tan 2002 \& 2005.

For example: Miklós 2009 and Føllesdal 2009.

For a critical discussion on such arguments that draw the analogy with friends, see Wellman 2001.

A short critical discussion of Hurka's account can be found in Arneson 2005, pp. 129-130.

viii Here I am assuming that if something has more goodness, then inter alia ceteris paribus it is more valuable. This is because the value of something is (partly) constituted by its goodness. Thus the more goodness, the more value there is, provided that everything else remains the same.

ix My thanks to the anonymous referees for asking me to highlight this.

$\mathrm{x} \quad$ My thanks to the anonymous referees for pointing this out.

\section{References}

Arneson, Richard. (2005) 'Do Patriotic Ties Limit Global Justice Duties?', The Journal of Ethics, 9 (1-2), 127-150.

Brock, Gillian. (2009) Global Justice. New York: Oxford University Press.

Caney, Simon. (1999) 'Nationality, Distributive Justice, and the Use of Force', Journal of Applied Philosophy, 16 (2), 123-138.

Caney, Simon. (2005) Justice Beyond Borders. New York: Oxford University Press.

Føllesdal, Andreas. (2009) 'Liberal Contractualism - Partial and Particularist, Impartial and Cosmopolitan' in S. Caney \& P. Lehning, (ed.), International Distributive Justice: Cosmopolitanism and Its Critics. London: Routledge.

Hurka, Thomas. (1997) 'The Justification of National Partiality' in Robert Mckim \& Jeff Mcmahan (ed), The Morality of Nationalism. New York: Oxford University Press, pp. 139-157.

Miklós, András. (2009) 'Nationalist Criticisms of Cosmopolitan Justice', Public Reason, 1 (1), 105124.

Miller, David. (2007) National Responsibility and Global Justice. New York: Oxford University Press.

Parfit, Derek. (1998) 'Equality and Priority' in Andrew Mason (ed.), Ideals of Equality. Oxford, Malden: Blackwell Publishers.

Tan, Kok-Chor. (2002) 'Liberal Nationalism and Cosmopolitan Justice', Ethical Theory and Moral Practice, 5, 431-461.

Tan, Kok-Chor. (2005) 'Cosmopolitan Impartiality and Patriotic Partiality' in Daniel Weinstock (ed), Global Justice, Global Institutions. Calgary: University of Calgary Press, pp. 165-192.

Tan, Kok-Chor. (2011) 'National Responsibility, Reparations and Distributive Justice', Critical Review of International and Political Philosophy, 11 (4), 449-464.

Wellman, Christopher Heath. (2001) 'Friends, Compatriots, and Special Political Obligations'

Political Theory, 29 (2), 217-236. 